\title{
Environmental triggers of dermatomyositis: a narrative review
}

\author{
Christina E. Bax ${ }^{1,2 \#}$, Spandana Maddukuri ${ }^{1,2 \#}$, Adarsh Ravishankar ${ }^{1,2 \#}$, Lisa Pappas-Taffer ${ }^{1,2}$, \\ Victoria P. Werth ${ }^{1,2}$ \\ ${ }^{1}$ Corporal Michael J. Crescenz VAMC, Philadelphia, PA, USA; ${ }^{2}$ Department of Dermatology, University of Pennsylvania, Philadelphia, PA, USA \\ Contributions: (I) Conception and design: CE Bax, S Maddukuri, A Ravishankar, VP Werth; (II) Administrative support: All authors; (III) Provision of \\ study materials or patients: All authors; (IV) Collection and assembly of data: All authors; (V) Data analysis and interpretation: CE Bax, S Maddukuri, \\ A Ravishankar, VP Werth; (VI) Manuscript writing: All authors; (VII) Final approval of manuscript: All authors. \\ \#These authors contributed equally to this work. \\ Correspondence to: Victoria P. Werth, MD. Department of Dermatology, Perelman Center for Advanced Medicine, Suite 1-330A, 3400 Civic Center \\ Boulevard, Philadelphia, PA 19104, USA. Email: werth@pennmedicine.upenn.edu.
}

\begin{abstract}
Dermatomyositis (DM) is an autoimmune disease that affects the skin, lungs, and muscle. Although the pathogenesis of DM is not completely understood, several environmental triggers have been linked to DM onset or flare. This article specifically examines the effects of herbal supplements, drugs, infections, ultraviolet (UV) radiation, and environmental pollutants on the onset or exacerbation of DM. Herbal supplements such as Spirulina platensis, Aphanizomenon flos-aquae, Chlorella, Echinacea, and Alfalfa have been implicated and are frequently used in health foods. Medications such as hydroxyurea, TNF- $\alpha$ inhibitors, immune checkpoint inhibitors (ICI), and penicillamine, as well as certain viral infections, such as parvovirus B19, coxsackie virus, polyomavirus, Epstein-Barr virus (EBV), hepatitis, influenza, and human immunodeficiency viruses (HIV) have been associated with DM onset. Bacterial infections and vaccinations have also been linked to the development of DM. Additional environmental factors, including UV radiation and air pollutants, such as silica, biological/mineral dust, and particulate air matter from vehicle and industrial emissions, may also play a role in DM pathogenesis. Overall, there is general agreement that an autoimmune attack of the skin, muscle, and lungs in DM can be triggered by various environmental factors and warrants further investigation.
\end{abstract}

Keywords: Dermatomyositis (DM); triggers; herbal supplements; drugs; infections; ultraviolet irradiation (UV irradiation); air pollution

Submitted May 07, 2020. Accepted for publication Jul 24, 2020.

doi: $10.21037 /$ atm-20-3719

View this article at: http://dx.doi.org/10.21037/atm-20-3719

\section{Introduction}

Dermatomyositis $(\mathrm{DM})$ is an autoimmune disease that affects the skin, lungs, and muscle, among other organs. The age of onset of DM has a bimodal distribution, with one peak occurring at ages 5-14 and the other at 4564 years (1). While the exact etiology and pathogenesis of $\mathrm{DM}$ are yet to be determined, there is general agreement that DM results from an autoimmune attack on affected organs and can be triggered by environmental factors, such as drugs, infections, ultraviolet (UV) exposure, and pollutant exposure in genetically susceptible individuals (1).
The objective of this article is to critically review the literature on environmental triggers of DM, specifically herbal supplements, drugs, infections, UV radiation, and environmental pollutants (Table 1). Our goal is to provide dermatologists, rheumatologists, and general practitioners with a framework for understanding and recognizing the various environmental triggers of DM in order to use this knowledge for the diagnosis, treatment, and prevention of the disease. In this narrative review we collected published peer-reviewed papers and abstracts from all available years, languages, study designs, and databases of coverage that we 
Table 1 Environmental triggers of DM

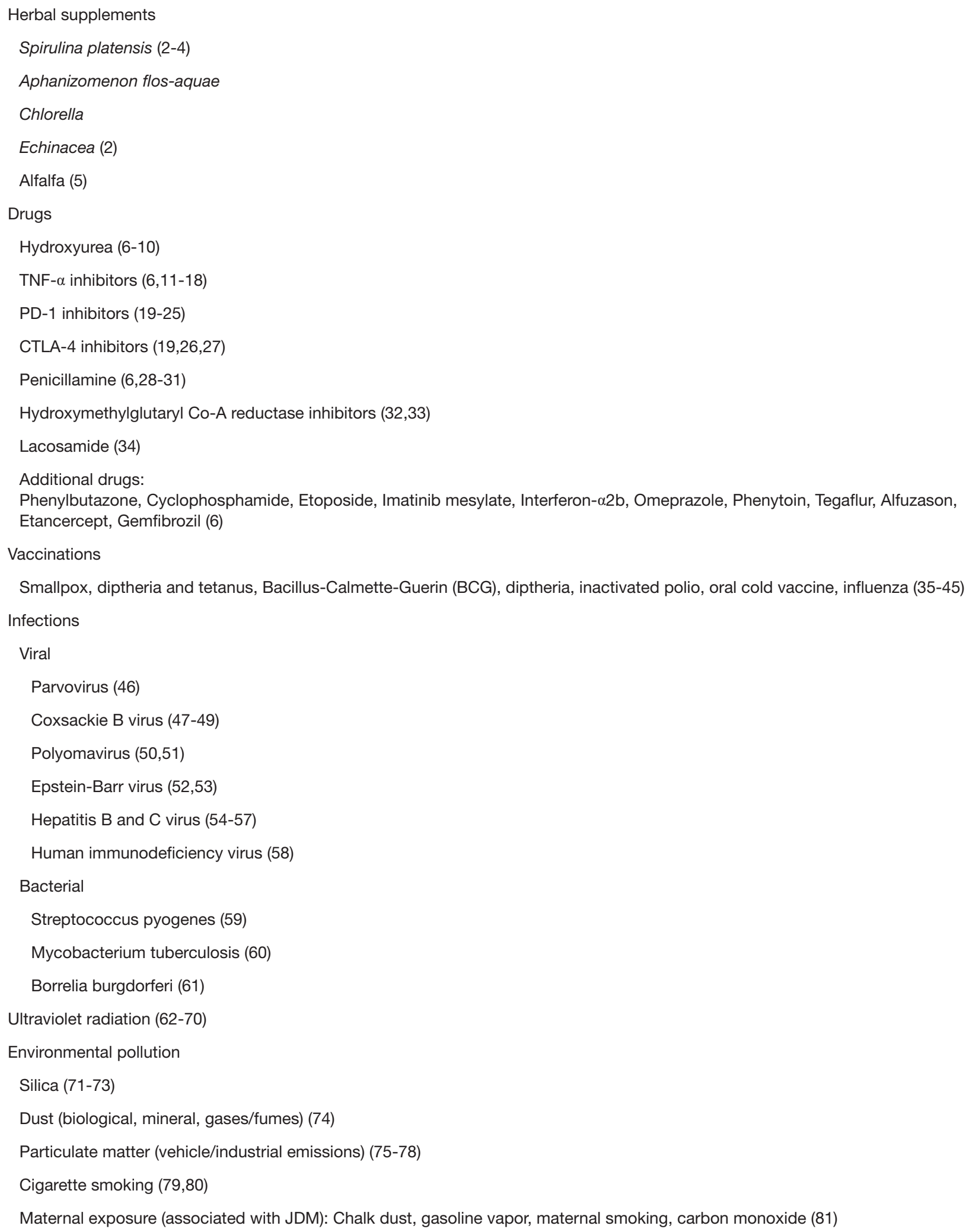

Table 1 (continued) 
Table 1 (continued)

\author{
Miscellaneous \\ Seasonal variation (82-86) \\ Pregnancy (87-93) \\ Liquid silicone filler rhinoplasty (94) \\ Silicone breast implants (95)
}

deemed essential for the goals of this review. We present the following article in accordance with the Narrative Review reporting checklist (available at http://dx.doi.org/10.21037/ atm-20-3719).

\section{DM and herbal supplements}

Various herbal supplements, including Spirulina platensis, Aphanizomenon flos-aquae, Chlorella, Echinacea and Alfalfa stimulate the immune system (96-102), and their use has been associated with autoimmune skin disease exacerbations and even disease onset $(2-5,103,104)$. Many patients with autoimmune skin diseases consume herbal supplements, with $35 \%$ to $69 \%$ of dermatology patients reporting complementary and alternative medicine use (105). Our preliminary survey data of DM, bullous pemphigoid, pemphigus vulgaris, and cutaneous and/or systemic lupus erythematosus patients show that DM patients had the highest rate of herbal supplement use compared with cutaneous lupus erythematosus and healthy controls, with $21.5 \%$ of DM patients reporting usage, and $14.6 \%$ reporting Spirulina consumption (4). In this context, it is important to consider that many of these herbal supplements are included in commercially available vitamin products, protein powder and weight loss mixes, and food items, either packaged in health food snacks and drinks like Naked fuices Green Machine shake or used in food establishments that serve smoothies and other made-toorder drinks.

Two case reports and one case series suggest that herbal supplements may cause DM onset or flare in susceptible patients $(2,3,5)$. In one report, a patient experienced acute new erythema of her face and hand knuckles one to two days after starting daily consumption of You're My Everything, a supplement containing Spirulina platensis, Aphanizomenon flos-aquae, organic cayenne pepper, and methylsulfonylmethane. After discontinuing the supplement and completing a 10 -day course of $40 \mathrm{mg}$ prednisone daily, she re-started You're My Everything and upon rechallenge, her rash worsened acutely in conjunction with significant swelling of her face, eyes, and ears. Prior biopsy findings and clinical exam were consistent with DM; however, despite appropriate treatment, cutaneous symptoms did not resolve completely (2). The temporal relationship between consumption and symptom onset, improvement with withdrawal, and response to re-challenge suggest that the herbal supplement was the likely culprit drug. In another report, a woman developed a widespread rash several days after taking a Spirulina supplement. She subsequently developed neck flexor and left proximal upper extremity weakness in association with an elevated serum creatine kinase $(1,268 \mathrm{IU} / \mathrm{mL})$. Clinical presentation and muscle histopathology were consistent with DM (3). Zeidi et al. (5) reported on three patients who developed DM or had a DM flare after ingesting Isalean ${ }^{\circledR}$ weight loss shake, which contains alfalfa and a proprietary enzyme blend of Aspergillus oryzae, Rhizopus oryzae, Trichoderma longibrachiatum, Saccharomyces cerevisiae, Bacillus subtilis, Ananas comosus, and Aspergiullus niger. In vitro testing showed that Isalean ${ }^{\circledR}$ dose-dependently stimulates peripheral blood mononuclear cell secretion of inflammatory cytokines TNF- $\alpha$, IFN- $\alpha$, and IFN- $\beta$, primarily via toll-like receptor 4 activation (5). Practitioners should be aware of the potential immunostimulatory effects of herbal supplements on DM and specifically ask their patients about possible consumption.

\section{DM and drugs}

Several drugs have been linked to DM onset or flare, including hydroxyurea, TNF- $\alpha$ inhibitors, ICI, and penicillamine (Table 1). Few controlled trials exist (11-13) and the majority of evidence is based on case reports. It is important to note that identifying culprit drugs and connecting them temporally with disease course is difficult for several reasons. First, many DM patients 
have underlying malignancies or autoimmune disorders, predisposing them to or triggering DM $(6,106)$. Second, patients are often on numerous drugs, and determining the offending agent can therefore be challenging. Third, the time course between beginning a drug and reported DM onset may be months to years, depending on the drug, making it difficult to link the two temporally (6). Thus, showing drug causality can be difficult or nearly impossible. For that reason, the World Health Organization (WHO) designed the Causality Assessment Algorithm to standardize the likelihood that a drug incited disease onset using four criteria: (I) temporal relationship; (II) no other attributable causes; (III) response to withdrawal; and (IV) response to re-challenge. Drugs are graded as certain, probable/likely, possible, unlikely, conditional/unclassified, or unassessable/ unclassifiable (107).

\section{Hydroxyurea}

Hydroxyurea is a cytotoxic agent most commonly used to treat myeloproliferative disorders, such as chronic myeloid leukemia (CML), polycythemia rubra vera, and essential thrombocythemia (108). It works by inhibiting ribonucleotide reductase, resulting in S-phase arrest and thereby halting de novo DNA synthesis $(108,109)$. Hydroxyurea has been frequently implicated in DMlike cutaneous eruptions (6-10); however, myopathy and new, DM-associated malignancy are typically not present $(9,110,111)$. In a review of 70 cases by Seidler and Gottlieb (6), hydroxyurea was the most common cause of druginduced DM, accounting for $51 \%$ of cases $(n=36 / 70)$. The authors found that compared to the non-hydroxyureatreated patients, hydroxyurea patients had no muscular weakness/myositis (vs. 79.4\%) and had a median time from start of drug to DM onset of 60.0 vs. 2.0 months for nonhydroxyurea-treated patients (6). The suspected culprit drug was withdrawn in $83.3 \%$ of the cases and nearly all patients had clinical improvement after drug withdrawal. In Vassallo et al. (112), 7/158 patients (4.4\%) on hydroxyurea for CML developed skin changes resembling Gottron's papules after long-term hydroxyurea use. The mechanism of action that causes DM-like manifestations is poorly understood. However, one possibility is that DM-like cutaneous eruptions arise due to the drug's cytotoxic effects from inhibiting both DNA repair and DNA synthesis $(109,113)$. It is thought that hydroxyurea inhibits the ribonucleotide reductase enzyme system thereby inhibiting cell DNA synthesis and reducing intracellular deoxyribonucleotide pools, ultimately leading to cell death (114). Another possibility is that the synergistic effects of hydroxyurea blocking DNA site repair and UV irradiation causing DNA strand breaks lead to DM manifestations $(110,112,113,115)$.

\section{TNF- $\alpha$ inbibitors}

TNF- $\alpha$ inhibitors, such as infliximab, adalimumab, and etanercept are frequently used for a wide range of autoimmune and rheumatological disorders, such as psoriasis, rheumatoid arthritis, ankylosing spondylitis, and Crohn's disease (116-118). There are numerous cases reporting a temporal associations between anti-TNF- $\alpha$ therapy in autoimmune disease patients and new onset DM (6,14-18). Although TNF- $\alpha$ inhibitors have been tested as potential therapies to treat DM, results have been mixed with many patients experiencing worsening of their disease (11-13). These results are paradoxical as high TNF- $\alpha$ is implicated in DM pathogenesis. For instance, the proinflammatory cytokine and its receptor are upregulated in DM and likely contribute to muscle inflammation and catabolism (119). Polymorphisms in the TNF- $\alpha$ promoter have also been linked to a greater risk of acquiring DM and increased severity in juvenile DM (JDM) $(120,121)$. The cytokine-shift hypothesis proposes one explanation for why pharmacologically blocking TNF- $\alpha$ counter-intuitively leads to DM onset or flare $(16,122)$. TNF- $\alpha$ inhibition increases type 1 interferon production $(12,119,121)$. The interferon signature plays a key role in DM pathogenesis by activating antigen presenting cells and stimulating autoantigen production, which in turn stimulates antibody production $(119,123)$. In an open pilot study of infliximab in patients with refractory inflammatory myopathies, several patients' DM acutely worsened and these flares were associated with increased type 1 interferon activity in both the blood and muscle (12). An alternate hypothesis is that TNF- $\alpha$ blockade may decrease cell apoptosis, leading to increased autoantibody production (124). As the use of TNF- $\alpha$ inhibitors continues to increase, health care professionals must be aware of the paradoxical, deleterious effects that these drugs may have in patients.

\section{ICI}

ICI, including PD-1 inhibitors such as pembrolizumab and nivolumab and CTLA-4 inhibitors such as ipilimumab, are 
increasingly being used worldwide and are an innovative approach to treating both solid and hematological malignancies (19). ICI aim to enhance the immune system's ability to recognize and destroy malignant cells. However, autoimmune-related adverse events, including autoimmune skin diseases such as DM, are increasingly being associated with ICI due to the enhanced activation of anti-tumor T cells and non-specific blockage of self-tolerance (19-21,125-127). Specifically, several case reports have noted new onset DM after pembrolizumab (21-23), nivolumab (20,24,25), and ipilimumab $(26,27)$ therapy. As the use of ICI to target malignancies continues to grow (128), it is important for physicians to be aware of and recognize ICI-induced DM.

\section{Penicillamine}

Penicillamine, a copper chelating agent used primarily in the treatment of Wilson disease as well as previously in rheumatoid arthritis, has also been implicated in DM onset or flare. In a review of 70 reported cases involving drug-induced DM, penicillamine was found to be the second most frequent drug to induce DM onset or flare (10/70 cases) (6). Disease remission occurred in all cases once penicillamine therapy was stopped. The majority of case reports are from the 1970s-1980s when penicillamine was more commonly used for rheumatoid arthritis (28-31). Nevertheless, it's important to recognize that the drug has frequently been associated with DM exacerbations.

\section{Additional drugs}

Hydroxymethylglutaryl Co-A reductase inhibitors are also drugs that have frequently been associated with DM $(32,33)$. Other DM-inducing drugs cited in Seidler and Gottlieb's review of 70 cases include: phenylbutazone, cyclophosphamide, etoposide, imatinib mesylate, interferon$\alpha 2 \mathrm{~b}$, omeprazole, phenytoin, tegafur, alfuzosin, etanercept, and gemfibrozil (6). Lacosamide (34) has also recently been associated with cases of new onset DM.

\section{Vaccinations}

Although rare, multiple cases have reported instances in which vaccines, including smallpox, diphtheria and tetanus, Bacillus Calmette-Guerin (BCG), inactivated polio, oral cold vaccine, and influenza (35-45), may have triggered DM.

\section{DM and infections}

In genetically susceptible individuals, viral, bacterial, and parasitic infections have been suspected to induce autoimmunity and even exacerbate existing autoimmune conditions (129). Epidemiological data shows that subsets of polymyositis (PM) and DM patients defined by various myositis-specific antibodies tend to develop disease at specific times of the year $(82,130)$. This seasonal clustering of disease onset could be indicative of a common environmental trigger such as infection (82). The relationship of infection to DM onset has been better evaluated in children. Two studies evaluated the roles of infections prior to development of JDM. One study identified clinical signs of infection three months before JDM onset in $71 \%$ of the 110 patients (131). Another study involving 286 children with JDM found frequent complaints of respiratory (57\%) and constitutional (56\%) symptoms three months before diagnosis of JDM. The authors believed this to be a viral prodrome before JDM onset (132). Although infection as a trigger has been heavily studied in JDM, infections have also been shown to play a role in adult DM onset.

\section{Parvovirus}

Parvovirus B19 (B19) is most known for causing disease in the pediatric population and is the classic cause of the childhood rash fifth disease or erythema infectiosum. B19 has been implicated in the pathogenesis of connective tissue diseases such as JDM (46). In one prospective study of seven patients who demonstrated clinical and/or serological signs supporting a diagnosis of connective tissue disease subsequent to B19 infection, five of the seven patients fulfilled the American College of Rheumatology's criteria for DM (46).

\section{Coxsackie B virus}

Coxsackie viruses are enteroviruses of the family Picornaviridae. Coxsackie B contains six serotypes that trigger illnesses ranging from gastrointestinal symptoms to pericarditis and myocarditis (47). One study sought to determine whether human response to Coxsackie B virus could be implicated in the pathogenesis of DM (48). Viral complement-fixation antibodies to Coxsackie B1, B2, and B4 were found significantly more frequently in the sera 
of $12 \mathrm{JDM}$ patients, who were tested within four months of JDM onset, than in the sera of their matched juvenile rheumatoid arthritis controls and from pediatric controls hospitalized for viral syndromes (48). Except in the cases of persistent antigenic stimulation of latent virus infection, complement-fixation antibodies can only be detected for a few months after the onset of viral infection (48). Another study reported elevated antibody titers to Coxsackie B3 in adult DM patients without malignancy when compared to controls with rheumatoid arthritis and normal healthy controls (49).

\section{Polyomavirus}

Human polyomavirus ( $\mathrm{HPyV}) 6$ and $\mathrm{HPyV} 7$ are closely related polyomavirus species and are thought to infect the skin of many healthy individuals in a latent or subclinical manner (50). However, recent studies revealed that HPyV6 and HPyV7 could infect and actively replicate in immunosuppressed patients causing the formation of pruritic, scaly brown plaques that, when biopsied, show a characteristic parakeratotic pattern called a "peacock plumage" (50). Nyugen et al. (50) demonstrated that both $\mathrm{HPyV} 6$ and $\mathrm{HPyV} 7$ are associated with rare, pruritic skin eruptions that have a distinct dyskeratotic histologic pattern by performing polymerase chain reaction for $\mathrm{HPyVs}$ on biopsies showing this "peacock plumage". They found high viral loads in lesional skin compared with normalappearing skin and concluded that $\mathrm{HPyV} 6$ and $\mathrm{HPyV} 7$ are associated with these rare, pruritic skin eruptions (50). This entity was described by Nyugen et al. as HPyV6- and $\mathrm{HPyV} 7$-associated pruritic and dyskeratotic dermatoses and had been previously identified in Wong-type DM, a rare variant of DM characterized by tiered parakeratosis with dyskeratosis or "peacock plumage". Matsumoto et al. (51) initially described the connection between Wong-type $\mathrm{DM}$ and Nyugen et al.'s finding of HPyV6- and HPyV7associated pruritic and dyskeratotic dermatoses and suggested further investigation for the relationship between $\mathrm{HPyV}$ infection and Wong-type DM.

\section{Epstein-Barr virus (EBV)}

EBV is a human herpesvirus that resides in memory B cells in a latent form. EBV has been linked to the development of a number of autoimmune disorders (52). A case-control study showed higher frequencies of anti-Epstein-Barr nuclear antigen 1 (EBNA1) antibodies at the onset of $\mathrm{DM} / \mathrm{PM}$ and the EBV genome was detected at a higher frequency in DM/PM patients than in their matched healthy control counterparts (53). This study also showed that the concurrence of malignancies, such as nasopharyngeal carcinoma, further increased the development of idiopathic inflammatory myositis (IIM) (53).

\section{Hepatitis B virus $(\mathrm{HBV})$ and Hepatitis C virus $(\mathrm{HCV})$}

$\mathrm{HBV}$ and $\mathrm{HCV}$ are viruses that can cause liver inflammation and damage. Both HBV and HCV can cause either acute or chronic illness. Occasionally, HBV infection has been reported to cause a variety of extrahepatic symptoms including PM and DM although the exact mechanism remains unknown (54). In certain cases of chronic hepatitis infection, hepatocellular carcinoma (HCC) develops and has been noted as the inciting factor for DM (55-57). In one 79-year-old female with HCV-associated HCC, DM developed 9 months after diagnosis with HCC and coincided with an enlargement of her tumor (55).

\section{Human immunodeficiency virus (HIV)}

The occurrence of DM has also been reported in the setting of HIV infection. With only four known cases, the development of DM in a patient with HIV is exceedingly rare, and occurred between 6-18 months after HIV diagnosis (58).

\section{Bacterial causes}

A case-control study (59) found increased frequency of streptococcal infection in those with JDM than in matched controls. A case series from Mexico (60) showed that of the 30 patients who developed systemic rheumatic disease after Mycobacterium tuberculosis infection, five were diagnosed with PM or DM. One case report (61) describes the development of DM subsequent to Borrelia burgdorferi infection, suggesting that this bacterial cause of Lyme disease may be an inducer of DM.

\section{DM and UV radiation}

Cutaneous features of DM including persistent erythema, increased prevalence in sun-exposed areas, and photoaggravation all suggest that $\mathrm{UV}$ radiation plays a 
strong role in disease pathogenesis $(62,63)$. In fact, Quain et al. (64) suggest that recurrent photosensitive dermatoses may be an initial presenting sign of DM and should prompt consideration of the diagnosis. The prevalence of DM increases significantly with decreasing geographical latitude from northern Europe (Reykjavik, Iceland) to southern Europe (Athens, Greece), suggesting that UV exposure may be implicated in DM pathogenesis (65). One study surveyed and performed photoprovocation testing on $19 \mathrm{DM}$ patients to further investigate the nature of photosensitivity in DM (66). Of these, seven patients reported increased photosensitivity and four reported aggravation of existing lesions or inducement of new lesions after photoprovocation (66). Formal UVB testing of these patients demonstrated a reduced minimal erythemal dose in nine patients (66). This study proposes that UV exposure correlates significantly with DM pathogenesis as exposure caused induction of new lesions and exacerbation of pre-existing lesions. The anti-Mi-2 antibody has been associated with UV exposure and is more common in DM patients living in regions with higher UV exposure (67). Patients with anti-Mi-2 antibody have also been reported to have increased severity and activity of DM (68). Additionally, increases in the DM-specific anti-TIF1- $\gamma$ antibody have been reported with decreasing latitudes, further highlighting potential mechanisms explaining the increased prevalence of DM closer to the equator (69). One study examined 919 patients from 15 locations to determine how geoclimatic factors influence the frequency of DM and associated autoantibodies around the world (70). This study found UV radiation intensity to be the strongest multivariate predictor of DM, followed by latitude as the second strongest predictor (70). Furthermore, UV radiation intensity was the geoclimatic variable most strongly related to the proportion of DM patients positive for the anti-Mi-2 antibody (70). UV exposure should be recognized as a prevalent environmental trigger of DM.

\section{DM and air pollution}

Occupational exposure has been linked to the onset of both adult DM and JDM. In one study of male construction workers in Sweden, occupational exposure to silica and inorganic dusts was associated with an increased risk of rheumatoid arthritis, systemic lupus erythematosus, systemic sclerosis, and DM (71) after accounting for age and smoking. Several other cases have also linked the association of silicosis and DM and PM $(72,73)$. In another study of 32 patients with antisynthetase syndrome patients, half of whom also had DM, patients with greater exposure to biological dust, mineral dust, or dust/gases/fumes had higher rates of interstitial lung disease than patients with low or no exposure, although it was not statistically significant (74). Such occupational exposure has also been linked with JDM. One study in Brazil analyzing pregnancy risk factors associated with a child developing JDM compared to healthy controls found that maternal exposure to chalk dust or gasoline vapor, maternal smoking, and carbon monoxide exposure (3.18-5.35 ppm) all increased the JDM risk (81).

It is well established that increased particulate matter in the air, such as from vehicle and industrial emissions, is associated with increased mortality $(75,76)$. Particulate matter has been shown to trigger the release of proinflammatory cytokines, including TNF- $\alpha$, IL-6, IL-1 $\beta$. MIP-1 $\alpha$, and GM-CSF (77). In a population study of Canadian patients, the likelihood of having a systemic autoimmune disease increased with the amount of fine particulate air pollution (76). Moreover, an analysis of the geospatial distribution of DM patients in the Philadelphia metropolitan area found that point sources of airborne pollutant matter, such as emissions from industrial and commercial sources, were associated with the presence of clinically amyopathic DM, but not classic DM (78).

Cigarette smoking is associated with varying phenotypic characteristics of DM. Schiffenbauer et al. (79) studied 465 patients with IIMs (58\% PM, $42 \% \mathrm{DM}$ ), finding that smokers were more likely to have PM, antisynthetase antibody, and anti-Jo-1 antibody. However, smokers were less likely to have anti-p155/140 antibody (79). Another European case study found similar results; among 557 Caucasian IIM patients (50\% PM, 38\% DM, 12\% overlap), smoking was associated with anti-Jo-1 antibody, which was more pronounced among patients with HLA-DRB1*03 (80).

\section{Miscellaneous triggers of DM}

Seasonal variations affect both the symptoms and the course of DM, with the most relapses occurring during the summer and spring $(83,84)$. However, studies have yet to find a consistent link between seasonal variations and DM onset. Sarkar et al. (85) analyzed the dates of disease onset of 268 PM patients and $235 \mathrm{DM}$ patients, finding no significant difference in seasonal variation between the two groups. 
While seasonal variations have not correlated with DM as a whole, seasonal variations correlate with the presence of DM autoantibodies (84). For example, Sarkar et al. (85) observed the onset of myositis among non-black patients with antisynthetase antibodies to be around March-April, and patients that tested negative for myositis autoantibodies to be around June-July. Leff et al. (82) found that the onset of weakness for anti-Jo-1 patients was April, and anti-SRP patients was November.

Seasonal variation in maternal exposure may also play a role for a subset of juvenile DM patients. Vegosen et al. (86) analyzed the birth dates of 307 juvenile IIM and 668 adult IIM compared to controls and did not find any significant difference between birth dates in either group. However, among Hispanic juvenile IIM patients, a seasonal variation was observed compared to Hispanic controls (October vs. year-round) and non-Hispanic juvenile IIM (October $v s$. May). Additionally, JDM patients who were anti-p155positive had a mean birthdate of February, while the mean birthdate of anti-p155 negative JDM patients was July (86).

Gestation also has effects on DM symptoms. In one study of $10 \mathrm{DM}$ patients and 21 pregnancies, while all patients continued to have rashes during pregnancy, the majority experienced improvement of weakness, rash, and arthritis during pregnancy (87). In one rare case, gestation may have triggered DM, with the patient experiencing onset of symptoms during gestation, which abated after a spontaneous termination of the pregnancy (88). Two types of pregnancy-related DM have been proposed: (I) DM presenting during pregnancy and (II) DM developing during the postpartum period (89). Three cases of postpartum DM development have been reported; one woman developing symptoms five days after delivery, another experiencing symptoms one month after normal delivery, and the last being diagnosed 15 days after cesarean section (89-91). Additionally, women have experienced exacerbation of DM symptoms during the postpartum period $(91,92)$. Overall, various factors during pregnancy such as exposure to fetal antigens, changes in maternal hormonal status, and the reactivation of certain viruses by pregnancy have been considered as triggers for the development of DM (93). Other miscellaneous triggers of DM include liquid silicone filler rhinoplasty and silicone breast implants $(94,95)$.

\section{Conclusions}

The factors that can cause disease and DM pathogenesis are still not fully understood $(119,133)$. However, herbal supplements and weight loss powders, drugs, infections, UV radiation, and pollution, are several environmental factors associated with DM onset and flares and may contribute to disease manifestation in genetically susceptible individuals. Physicians should consider possible inciting environmental factors, as in some cases, such as with herbal supplements and drugs, removal of the environmental factor may improve DM symptoms and clinical course. It is important to continue to investigate the association between environmental risk factors and DM onset or flare in order to better understand the disease and to guide patients in best practices, as well as to aid in developing better therapies.

\section{Acknowledgments}

Funding: NIH R01AR071653. This work was supported by the United States Department of Veterans Affairs (Veterans Health Administration, Office of Research and Development and Biomedical Laboratory Research and Development). One of us (CEB) was supported by the National Center for Advancing Translational Sciences of the National Institutes of Health under award number TL1TR001880.

\section{Footnote}

Reporting Checklist: The authors have completed the Narrative Review reporting checklist. Available at http:// dx.doi.org/10.21037/atm-20-3719

Provenance and Peer Review: This article was commissioned by the Guest Editors (Drs. Richard D. Sontheimer, M. Kari Connolly, David F. Fiorentino, and Victoria P. Werth) for the series "Rheumatologic Skin Disease" published in Annals of Translational Medicine. The article was sent for external peer review organized by the Guest Editors and the editorial office.

Conflicts of Interest: All authors have completed the ICMJE uniform disclosure form (available at http://dx.doi. org/10.21037/atm-20-3719). The series "Rheumatologic Skin Disease" was commissioned by the editorial office without any funding or sponsorship. VPW served as the unpaid Guest Editor of the series. VPW reports personal fees from EMD Serona, personal fees from Vielo, grants and personal fees from Pfizer, personal fees from Idera, 
personal fees from Octapharma, grants and personal fees from CSL Behring, grants from Corbus Pharmaceuticals, outside the submitted work; In addition, VPW has a patent CDASI with royalties paid. The authors have no other conflicts of interest to declare.

Ethical Statement: The authors are accountable for all aspects of the work in ensuring that questions related to the accuracy or integrity of any part of the work are appropriately investigated and resolved.

Open Access Statement: This is an Open Access article distributed in accordance with the Creative Commons Attribution-NonCommercial-NoDerivs 4.0 International License (CC BY-NC-ND 4.0), which permits the noncommercial replication and distribution of the article with the strict proviso that no changes or edits are made and the original work is properly cited (including links to both the formal publication through the relevant DOI and the license). See: https://creativecommons.org/licenses/by-nc-nd/4.0/.

\section{References}

1. Bogdanov I, Kazandjieva J, Darlenski R, et al. Dermatomyositis: Current concepts. Clin Dermatol 2018;36:450-8.

2. Lee AN, Werth VP. Activation of Autoimmunity Following Use of Immunostimulatory Herbal Supplements. Arch Dermatol 2004;140:723-7.

3. Konno T, Umeda Y, Umeda M, et al. A case of inflammatory myopathy with widely skin rash following use of supplements containing Spirulina. Rinsho Shinkeigaku 2011;51:330-3.

4. Adarsh Ravishankar DY, Bax CE, Concha JS, et al. Usage of immunostimulatory herbal supplements in patients with autoimmune skin diseases. 2020.

5. Zeidi M, Chansky PB, Werth VP. Acute onset/flares of dermatomyositis following ingestion of IsaLean herbal supplement: Clinical and immunostimulatory findings. J Am Acad Dermatol 2019;80:801-4.

6. Seidler AM, Gottlieb AB. Dermatomyositis induced by drug therapy: a review of case reports. J Am Acad Dermatol 2008;59:872-80.

7. Niklas K, Niklas AA, Majewski D, et al. Rheumatic diseases induced by drugs and environmental factors: the state-of-the-art - part two. Reumatologia 2016;54:165-9.

8. Nofal A, El-Din ES. Hydroxyurea-induced dermatomyositis: true amyopathic dermatomyositis or dermatomyositis-like eruption? Int J Dermatol 2012;51:535-41.

9. Dacey MJ, Callen JP. Hydroxyurea-induced dermatomyositis-like eruption. J Am Acad Dermatol 2003;48:439-41.

10. Suehiro M, Kishimoto S, Wakabayashi T, et al. Hydroxyurea dermopathy with a dermatomyositislike eruption and a large leg ulcer. Br J Dermatol 1998;139:748-9.

11. Rouster-Stevens KA, Ferguson L, Morgan G, et al. Pilot study of etanercept in patients with refractory juvenile dermatomyositis. Arthritis Care Res (Hoboken) 2014;66:783-7.

12. Dastmalchi M, Grundtman C, Alexanderson H, et al. A high incidence of disease flares in an open pilot study of infliximab in patients with refractory inflammatory myopathies. Ann Rheum Dis 2008;67:1670-7.

13. Schiffenbauer A, Garg M, Castro C, et al. A randomized, double-blind, placebo-controlled trial of infliximab in refractory polymyositis and dermatomyositis. Semin Arthritis Rheum 2018;47:858-64.

14. Brunasso AM, Aberer W, Massone C. New onset of dermatomyositis/polymyositis during antiTNF- $\alpha$ therapies: a systematic literature review. ScientificWorldJournal. 2014;2014:179180.

15. Riolo G, Towheed TE. Anti-tumor necrosis factor inhibitor therapy-induced dermatomyositis and fasciitis. J Rheumatol 2012;39:192-4.

16. Klein R, Rosenbach M, Kim EJ, et al. Tumor necrosis factor inhibitor-associated dermatomyositis. Arch Dermatol 2010;146:780-4.

17. Liu SW, Velez NF, Lam C, et al. Dermatomyositis induced by anti-tumor necrosis factor in a patient with juvenile idiopathic arthritis. JAMA Dermatol 2013;149:1204-8.

18. Brunasso AM, Scocco GL, Massone C. Dermatomyositis during adalimumab therapy for rheumatoid arthritis. J Rheumatol 2010;37:1549-50.

19. Liewluck T, Kao JC, Mauermann ML. PD-1 Inhibitorassociated Myopathies: Emerging Immune-mediated Myopathies. J Immunother 2018;41:208-11.

20. Kosche C, Stout M, Sosman J, et al. Dermatomyositis in a patient undergoing nivolumab therapy for metastatic melanoma: a case report and review of the literature. Melanoma Res 2020;30:313-6.

21. Marano AL, Clarke JM, Morse MA, et al. Subacute cutaneous lupus erythematosus and dermatomyositis 
associated with anti-programmed cell death 1 therapy. Br J Dermatol 2019;181:580-3.

22. Berger M, Legeay AL, Souci S, et al. Pembrolizumabinduced dermatomyositis in a patient with metastatic melanoma. Eur J Cancer 2018;104:227-30.

23. Belum VR, Benhuri B, Postow MA, et al. Characterisation and management of dermatologic adverse events to agents targeting the PD-1 receptor. Eur J Cancer 2016;60:12-25.

24. Yu WY, North JP, McCalmont TH, et al. Wong-type dermatomyositis during anti-PD-1 therapy. JAAD Case Rep 2018;4:1049-51.

25. Kudo F, Watanabe Y, Iwai Y, et al. Advanced lung adenocarcinoma with nivolumab-associated dermatomyositis. Intern Med 2018;57:2217-21.

26. Yamaguchi Y, Abe R, Haga N, et al. A case of drugassociated dermatomyositis following ipilimumab therapy. Eur J Dermatol 2016;26:320-1.

27. Sheik Ali S, Goddard AL, Luke JJ, et al. Drug-Associated Dermatomyositis Following Ipilimumab Therapy: A Novel Immune-Mediated Adverse Event Associated With Cytotoxic T-Lymphocyte Antigen 4 Blockade. JAMA Dermatology 2015;151:195-9.

28. Kolsi R, Bahloul Z, Hachicha J, et al. Dermatopolymyositis induced by D-penicillamine in rheumatoid polyarthritis.

Apropos of 1 case with review of the literature. Rev Rhum Mal Osteoartic 1992;59:341-4.

29. Carroll GJ, Will RK, Peter JB, et al. Penicillamine induced polymyositis and dermatomyositis. J Rheumatol 1987;14:995-1001.

30. Fernandes L, Swinson DR, Hamilton EB. Dermatomyositis complicating penicillamine treatment. Ann Rheum Dis 1977;36:94-5.

31. Simpson NB, Golding JR. Dermatomyositis induced by penicillamine. Acta Derm Venereol 1979;59:543-4.

32. Zaraa IR, Labbène I, Mrabet D, et al. Simvastatin-induced dermatomyositis in a 50-year-old man. BMJ Case Rep 2011;2011:bcr0220113832.

33. Borges IBP, Silva MG, Misse RG, et al. Lipid-lowering agent-triggered dermatomyositis and polymyositis: a case series and literature review. Rheumatol Int 2018;38:293-301.

34. Gaffney RG, Tarazi M, Werth VP. Drug-induced dermatomyositis after lacosamide: A case report. JAAD Case Rep 2018;4:584-5.

35. Stübgen JP. A review on the association between inflammatory myopathies and vaccination. Autoimmun Rev 2014;13:31-9.
36. Bitnum S, Daeschner Jr CW, Travis LB, et al. Dermatomyositis. J Pediatr 1964;64:101-31.

37. Thieffry S, Arthuis M, Martin C, et al. Infantile dermatomyositis. Study of 8 personal cases. Ann Pediatr (Paris) 1967;14:554-78.

38. Machtey I, Bandmann M, Palant A. Unusual reaction to BCG. Lancet (London, England) 1968;1:140-1.

39. Cotterill JA, Shapiro H. Dermatomyositis after immunisation. Lancet 1978;2:1158-9.

40. Ehrengut $W$. Dermatomyositis and vaccination. Lancet 1978;1:1040-1.

41. Kåss E, Straume S, Munthe E. Dermatomyositis after B.C.G. vaccination. Lancet 1978;1:772.

42. Fernández-Fúnez A, Polo Romero FJ. Juvenile dermatomyositis concomitant with hepatitis $\mathrm{B}$ vaccination. Med Clin (Barc) 1998;111:675.

43. Ferri C, Colaci M, Manzini CU, et al. Polymyositis following Pandemic Influenza A (H1N1) and 200910 Seasonal Trivalent Vaccines. Case Rep Rheumatol 2012;2012:836930.

44. Winkelmann RK. Influenza vaccine and dermatomyositis. Lancet 1982;2:495.

45. Jani FM, Gray JP, Lanham J. Influenza vaccine and dermatomyositis. Vaccine 1994;12:1484.

46. Crowson AN, Magro CM, Dawood MR. A causal role for parvovirus B19 infection in adult dermatomyositis and other autoimmune syndromes. J Cutan Pathol 2000;27:505-15.

47. Moore M, Kaplan MH, McPhee J, et al. Epidemiologic, clinical, and laboratory features of Coxsackie B1-B5 infections in the United States, 1970-79. Public Health Rep 1984;99:515-22.

48. Christensen ML, Pachman LM, Schneiderman R, et al. Prevalence of Coxsackie $\mathrm{B}$ virus antibodies in patients with juvenile dermatomyositis. Arthritis Rheum 1986;29:1365-70.

49. Nishikai M. Coxsackievirus infection and the development of polymyositis/dermatomyositis. Rheumatol Int 1994;14:43-6.

50. Nguyen KD, Lee EE, Yue Y, et al. Human polyomavirus 6 and 7 are associated with pruritic and dyskeratotic dermatoses. J Am Acad Dermatol 2017;76:932-40.e3.

51. Matsumoto A, Wang R, Carlson JA. Columnar dyskeratosis-A clue to Wong-type dermatomyositis? J Cutan Pathol 2017;44:813-4.

52. Posnett DN. Herpesviruses and autoimmunity. Curr Opin Investig Drugs 2008;9:505-14. 
53. Chen DY, Chen YM, Lan JL, et al. Polymyositis/ dermatomyositis and nasopharyngeal carcinoma: the Epstein-Barr virus connection? J Clin Virol 2010;49:290-5.

54. Cacoub P, Terrier B. Hepatitis B-related autoimmune manifestations. Rheum Dis Clin North Am 2009;35:125-37.

55. Toshikuni N, Torigoe R, Mitsunaga M, et al. Dermatomyositis associated with hepatocellular carcinoma in an elderly female patient with hepatitis $\mathrm{C}$ virus-related liver cirrhosis. World J Gastroenterol 2006;12:1641-4.

56. Chou JW, Lin YL, Cheng KS, et al. Dermatomyositis Induced by Hepatitis B Virus-related Hepatocellular Carcinoma: A Case Report and Review of the Literature. Intern Med 2017;56:1831-7.

57. Yang SY, Cha BK, Kim G, et al. Dermatomyositis associated with hepatitis B virus-related hepatocellular carcinoma. Korean J Intern Med 2014;29:231-5.

58. Carroll MB, Holmes R. Dermatomyositis and HIV infection: case report and review of the literature. Rheumatol Int 2011;31:673-9.

59. Koch MJ, Brody JA, Gillespie MM. Childhood polymyositis: a case-control study. Am J Epidemiol 1976;104:627-31.

60. Hernández-Cruz B, Sifuentes-Osornio J, Ponce-de-Leon Rosales S, et al. Mycobacterium tuberculosis infection in patients with systemic rheumatic diseases. A case-series. Clin Exp Rheumatol 1999;17:289-96.

61. Nguyen H, Le C, Nguyen H. Acute lyme infection presenting with amyopathic dermatomyositis and rapidly fatal interstitial pulmonary fibrosis: a case report. J Med Case Rep 2010;4:187.

62. Roelandts R. The diagnosis of photosensitivity. Arch Dermatol 2000;136:1152-7.

63. Sontheimer RD. Photoimmunology of lupus erythematosus and dermatomyositis: a speculative review. Photochem Photobiol 1996;63:583-94.

64. Quain RD, Werth VP. Management of cutaneous dermatomyositis: current therapeutic options. Am J Clin Dermatol 2006;7:341-51.

65. Hengstman GJ, van Venrooij WJ, Vencovsky J, et al. The relative prevalence of dermatomyositis and polymyositis in Europe exhibits a latitudinal gradient. Ann Rheum Dis 2000;59:141-2.

66. Dourmishev L, Meffert H, Piazena H. Dermatomyositis: comparative studies of cutaneous photosensitivity in lupus erythematosus and normal subjects. Photodermatol Photoimmunol Photomed 2004;20:230-4.

67. Ogawa-Momohara M, Muro Y, Akiyama M. Anti-
Mi-2 antibody titers and cutaneous manifestations in dermatomyositis. Available online: https://onlinelibrary. wiley.com/doi/full/10.1002/cia2.12048

68. Matsuda T, Ueda-Hayakawa I, Kambe N, et al. Four cases of anti-Mi-2 antibody-positive dermatomyositis: relationship between anti-Mi-2 antibody titre and disease severity and activity. J Eur Acad Dermatol Venereol 2018;32:e233-4.

69. Parkes JE, Rothwell S, Oldroyd A, et al. Genetic background may contribute to the latitude-dependent prevalence of dermatomyositis and anti-TIF1- $\gamma$ autoantibodies in adult patients with myositis. Arthritis Res Ther 2018;20:117.

70. Okada S, Weatherhead E, Targoff IN, et al. Global surface ultraviolet radiation intensity may modulate the clinical and immunologic expression of autoimmune muscle disease. Arthritis Rheum 2003;48:2285-93.

71. Blanc PD, Järvholm B, Torén K. Prospective risk of rheumatologic disease associated with occupational exposure in a cohort of male construction workers. Am J Med 2015;128:1094-101.

72. Yang Y, Fujita J, Tokuda M, et al. Clinical features of polymyositis/dermatomyositis associated with silicosis and a review of the literature. Rheumatol Int 2001;20:235-8.

73. Koeger AC, Alcaix D, Rozenberg S, et al. Occupational exposure to silicon and dermatopolymyositis. 3 cases. Ann Med Interne (Paris) 1991;142:409-13.

74. Labirua-Iturburu A, Selva-O'Callaghan A, Zock JP, et al. Occupational exposure in patients with the antisynthetase syndrome. Clin Rheumatol 2014;33:221-5.

75. Dockery DW, Pope CA 3rd, Xu X, et al. An association between air pollution and mortality in six U.S. cities. N Engl J Med 1993;329:1753-9.

76. Bernatsky S, Smargiassi A, Barnabe C, et al. Fine particulate air pollution and systemic autoimmune rheumatic disease in two Canadian provinces. Environ Res 2016;146:85-91.

77. van Eeden SF, Tan WC, Suwa T, et al. Cytokines involved in the systemic inflammatory response induced by exposure to particulate matter air pollutants $(\mathrm{PM}(10))$. Am J Respir Crit Care Med 2001;164:826-30.

78. Pearson DR, Werth VP. Geospatial Correlation of Amyopathic Dermatomyositis With Fixed Sources of Airborne Pollution: A Retrospective Cohort Study. Front Med (Lausanne) 2019;6:85.

79. Schiffenbauer A, Faghihi-Kashani S, O'Hanlon TP, et al. The effect of cigarette smoking on the clinical 
and serological phenotypes of polymyositis and dermatomyositis. Semin Arthritis Rheum 2018;48:504-12.

80. Chinoy H, Adimulam S, Marriage F, et al. Interaction of HLA-DRB $1{ }^{*} 03$ and smoking for the development of anti-Jo-1 antibodies in adult idiopathic inflammatory myopathies: a European-wide case study. Ann Rheum Dis 2012;71:961-5.

81. Orione MA, Silva CA, Sallum AM, et al. Risk factors for juvenile dermatomyositis: exposure to tobacco and air pollutants during pregnancy. Arthritis Care Res (Hoboken) 2014;66:1571-5.

82. Leff RL, Burgess SH, Miller FW, et al. Distinct seasonal patterns in the onset of adult idiopathic inflammatory myopathy in patients with anti-Jo-1 and anti-signal recognition particle autoantibodies. Arthritis Rheum 1991;34:1391-6.

83. Phillips BA, Zilko PJ, Garlepp MJ, et al. Seasonal occurrence of relapses in inflammatory myopathies: a preliminary study. J Neurol 2002;249:441-4.

84. Prieto S, Grau JM. The geoepidemiology of autoimmune muscle disease. Autoimmun Rev 2010;9:A330-4.

85. Sarkar K, Weinberg CR, Oddis CV, et al. Seasonal influence on the onset of idiopathic inflammatory myopathies in serologically defined groups. Arthritis Rheum 2005;52:2433-8.

86. Vegosen LJ, Weinberg CR, O'Hanlon TP, et al. Seasonal birth patterns in myositis subgroups suggest an etiologic role of early environmental exposures. Arthritis Rheum 2007;56:2719-28.

87. Miller G, Moore E, Valenzuela A, et al. Dermatomyositis and Pregnancy: Assessment of Disease Activity and Pregnancy Outcomes Complicated by Maternal Dermatomyositis. Arthritis Rheumatol 2016. Available online: https://acrabstracts.org/abstract/dermatomyositisand-pregnancy-assessment-of-disease-activity-andpregnancy-outcomes-complicated-by-maternaldermatomyositis/

88. Kofteridis DP, Malliotakis PI, Sotsiou F, et al. Acute onset of dermatomyositis presenting in pregnancy with rhabdomyolysis and fetal loss. Scand J Rheumatol 1999;28:192-4.

89. Kanoh H, Izumi T, Seishima M, et al. A case of dermatomyositis that developed after delivery: the involvement of pregnancy in the induction of dermatomyositis. Br J Dermatol 1999;141:897-900.

90. Suwa A, Hirakata M, Tsuzaka K, et al. Spontaneous remission of dermatomyositis which developed one month after normal delivery. Ryumachi 1992;32:73-9.

91. Gutiérrez G, Dagnino R, Mintz G. Polymyositis/ dermatomyositis and pregnancy. Arthritis Rheum 1984;27:291-4.

92. Ishii N, Ono H, Kawaguchi T, et al. Dermatomyositis and pregnancy. Case report and review of the literature. Dermatologica 1991;183:146-9.

93. Awatef K, Salim G, Zahra MF. A rare case of dermatomyositis revealed during pregnancy with good outcome. Pan Afr Med J 2016;23:117.

94. Hu HC, Cho HY, Chiu YH. Dermatomyositis Induced by Filler Rhinoplasty Using Liquid Silicone. JAMA Otolaryngol Head Neck Surg 2020;146:205-6.

95. Selva-O'Callaghan A, Tura JM, Grau-Junyent JM, et al. Silicone gel filled breast implants and dermatomyositis. Clin Exp Rheumatol 2004;22:376.

96. Pugh N, Ross SA, ElSohly HN, et al. Isolation of three high molecular weight polysaccharide preparations with potent immunostimulatory activity from Spirulina platensis, aphanizomenon flos-aquae and Chlorella pyrenoidosa. Planta Medica 2001;67:737-42.

97. Løbner M, Walsted A, Larsen R, et al. Enhancement of human adaptive immune responses by administration of a high-molecular-weight polysaccharide extract from the cyanobacterium Arthrospira platensis. J Med Food 2008;11:313-22.

98. Ravi M, De SL, Azharuddin S, et al. The beneficial effects of Spirulina focusing on its immunomodulatory and antioxidant properties. Nutr Diet Suppl 2010;2:73-83.

99. Pugh N, Pasco DS. Characterization of human monocyte activation by a water soluble preparation of Aphanizomenon flos-aquae. Phytomedicine 2001;8:445-53.

100.Hirahashi T, Matsumoto M, Hazeki K, et al. Activation of the human innate immune system by Spirulina: augmentation of interferon production and NK cytotoxicity by oral administration of hot water extract of Spirulina platensis. Int Immunopharmacol 2002;2:423-34.

101. Finamore A, Palmery M, Bensehaila S, et al. Antioxidant, Immunomodulating, and Microbial-Modulating Activities of the Sustainable and Ecofriendly Spirulina. Oxid Med Cell Longev 2017;2017:3247528..

102. Stimpel M, Proksch A, Wagner H, et al. Macrophage activation and induction of macrophage cytotoxicity by purified polysaccharide fractions from the plant Echinacea purpurea. Infect Immun 1984;46:845-9.

103. Di Lorenzo C, Ceschi A, Kupferschmidt H, et al. Adverse effects of plant food supplements and botanical 
preparations: a systematic review with critical evaluation of causality. Br J Clin Pharmacol 2015;79:578-92.

104.Kraigher O, Wohl Y, Gat A, et al. A mixed immunoblistering disorder exhibiting features of bullous pemphigoid and pemphigus foliaceus associated with Spirulina algae intake: Immunoblistering disorder associated with Spirulina algae intake. Int J Dermatol 2008;47:61-3.

105.Ernst E. The usage of complementary therapies by dermatological patients: a systematic review. Br J Dermatol 2000;142:857-61.

106. Miller FW, Cooper RG, Vencovský J, et al. Genomewide association study of dermatomyositis reveals genetic overlap with other autoimmune disorders. Arthritis Rheum 2013;65:3239-47.

107. The use of the WHO-UMC system for standardised case causality assessment The Uppsala Monitoring Centre. Available online: https://www.who.int/medicines/areas/ quality_safety/safety_efficacy/WHOcausality_assessment. pdf. Accessed 4/13/20.

108. Madaan K, Kaushik D, Verma T. Hydroxyurea: a key player in cancer chemotherapy. Expert Rev Anticancer Ther 2012;12:19-29.

109. Yarbro JW. Mechanism of action of hydroxyurea. Semin Oncol 1992;19:1-10.

110. Kalajian AH, Cely SJ, Malone JC, et al. Hydroxyureaassociated dermatomyositis-like eruption demonstrating abnormal epidermal p53 expression: a potential premalignant manifestation of chronic hydroxyurea and UV radiation exposure. Arch Dermatol 2010;146:305-10.

111. Senet P, Aractingi S, Porneuf M, et al. Hydroxyureainduced dermatomyositis-like eruption. Br J Dermatol 1995;133:455-9.

112. Vassallo C, Passamonti F, Merante S, et al. Mucocutaneous changes during long-term therapy with hydroxyurea in chronic myeloid leukaemia. Clin Exp Dermatol 2001;26:141-8.

113.Zaccaria E, Cozzani E, Parodi A. Secondary cutaneous effects of hydroxyurea: possible pathogenetic mechanisms. J Dermatolog Treat 2006;17:176-8.

114. Boyd AS, Neldner KH. Hydroxyurea therapy. J Am Acad Dermatol 1991;25:518-24.

115. Francis AA, Blevins RD, Carrier WL, et al. Inhibition of DNA repair in ultraviolet-irradiated human cells by hydroxyurea. Biochim Biophys Acta 1979;563:385-92.

116. Komaki Y, Yamada A, Komaki F, et al. Efficacy, safety and pharmacokinetics of biosimilars of anti-tumor necrosis factor-alpha agents in rheumatic diseases; A systematic review and meta-analysis. J Autoimmun 2017;79:4-16.

117. Gomollón F, Dignass A, Annese V, et al. 3rd European Evidence-based Consensus on the Diagnosis and Management of Crohn's Disease 2016: Part 1: Diagnosis and Medical Management. J Crohns Colitis 2017;11:3-25.

118. Chima M, Lebwohl M. TNF inhibitors for psoriasis. Semin Cutan Med Surg 2018;37:134-42.

119. Kao L, Chung L, Fiorentino DF. Pathogenesis of dermatomyositis: role of cytokines and interferon. Curr Rheumatol Rep 2011;13:225-32.

120. Mamyrova G, O'Hanlon TP, Sillers L, et al. Cytokine gene polymorphisms as risk and severity factors for juvenile dermatomyositis. Arthritis Rheum 2008;58:3941-50.

121. Salomonsson S, Lundberg IE. Cytokines in idiopathic inflammatory myopathies. Autoimmunity 2006;39:177-90.

122. Singh VK, Mehrotra S, Agarwal SS. The paradigm of Th1 and Th2 cytokines: its relevance to autoimmunity and allergy. Immunol Res 1999;20:147-61.

123.Huard C, Gulla SV, Bennett DV, et al. Correlation of cutaneous disease activity with type 1 interferon gene signature and interferon beta in dermatomyositis. Br J Dermatol 2017;176:1224-30.

124. Lorenz HM, Herrmann M, Winkler T, et al. Role of apoptosis in autoimmunity. Apoptosis 2000;5:443-9.

125.Lin J, Xue M, Gao M, et al. Toripalimab-Induced Dermatomyositis in a Patient with Metastatic Melanoma. Dermatol Ther (Heidelb) 2020;10:863-7.

126. Sibaud V. Dermatologic Reactions to Immune Checkpoint Inhibitors: Skin Toxicities and Immunotherapy. Am J Clin Dermatol 2018;19:345-61.

127. Cappelli LC, Gutierrez AK, Bingham CO 3rd, et al. Rheumatic and Musculoskeletal Immune-Related Adverse Events Due to Immune Checkpoint Inhibitors: A Systematic Review of the Literature. Arthritis Care Res (Hoboken) 2017;69:1751-63.

128. Tang J, Yu JX, Hubbard-Lucey VM, et al. The clinical trial landscape for PD1/PDL1 immune checkpoint inhibitors. Available online: https://www.nature.com/articles/ nrd.2018.210

129.Zampieri S, Ghirardello A, Iaccarino L, et al. Polymyositisdermatomyositis and infections. Autoimmunity 2006;39:191-6.

130.Nishina N, Sato S, Masui K, et al. Seasonal and residential clustering at disease onset of anti-MDA5-associated interstitial lung disease. RMD Open 2020;6:e001202.

131. Manlhiot C, Liang L, Tran D, et al. Assessment 
of an infectious disease history preceding juvenile dermatomyositis symptom onset. Rheumatology (Oxford) 2008;47:526-9.

132.Pachman LM, Lipton R, Ramsey-Goldman R, et al. History of infection before the onset of juvenile dermatomyositis: results from the National Institute of Arthritis and Musculoskeletal and Skin Diseases Research Registry. Arthritis Rheum 2005;53:166-72.

133. Thompson C, Piguet V, Choy E. The pathogenesis of dermatomyositis. Br J Dermatol 2018;179:1256-62.

Cite this article as: Bax CE, Maddukuri S, Ravishankar A, Pappas-Taffer L, Werth VP. Environmental triggers of dermatomyositis: a narrative review. Ann Transl Med 2021;9(5):434. doi: 10.21037/atm-20-3719 